\title{
PD-1/PD-L1 checkpoint inhibitors during late stages of life: an ad-hoc analysis from a large multicenter cohort
}

Daniele Santini', Tea Zeppola', Marco Russano ${ }^{1}$, Fabrizio Citarella' ${ }^{1}$, Cecilia Anesi', Sebastiano Buti², Marco Tucci ${ }^{3,4}$, Alessandro Russo ${ }^{5}$, Maria Chiara Sergi ${ }^{3}$, Vincenzo Adamo ${ }^{5}$, Luigia S. Stucci ${ }^{3}$, Melissa Bersanelli $^{2,6}$, Giulia Mazzaschi ${ }^{2}$, Francesco Spagnolo ${ }^{7}$, Francesca Rastelli ${ }^{8}$, Francesca Chiara Giorgi ${ }^{8}$, Raffaele Giusti ${ }^{9}$, Marco Filetti ${ }^{9}$, Paolo Marchetti ${ }^{9,10,11}$, Andrea Botticelli ${ }^{10,11}$, Alain Gelibter ${ }^{11}$, Marco Siringo ${ }^{11}$, Marco Ferrari ${ }^{12}$, Riccardo Marconcini ${ }^{12}$, Maria Giuseppa Vitale ${ }^{13}$, Linda Nicolardi ${ }^{14}$, Rita Chiari ${ }^{14}$, Michele Ghidini ${ }^{15}$, Olga Nigro ${ }^{16}$, Francesco Grossi ${ }^{17}$, Michele De Tursi ${ }^{18}$, Pietro Di Marino ${ }^{19}$, Laura Pala ${ }^{20}$, Paola Queirolo ${ }^{20}$, Sergio Bracarda ${ }^{21}$, Serena Macrini ${ }^{21}$, Stefania Gori' ${ }^{22}$, Alessandro Inno ${ }^{22}$, Federica Zoratto ${ }^{23}$, Enrica T. Tanda ${ }^{7,24}$, Domenico Mallardo ${ }^{25}$, Maria Grazia Vitale ${ }^{25}$, Thomas Talbot ${ }^{26}$, Paolo A. Ascierto ${ }^{25}$, David J. Pinato ${ }^{26,27,}$ Corrado Ficorella ${ }^{28,29}$, Giampiero Porzio ${ }^{28}$ and Alessio Cortellini ${ }^{26,29^{*}}$ (1)

\begin{abstract}
Background: The favourable safety profile and the increasing confidence with immune checkpoint inhibitors (ICls) might have boosted their prescription in frail patients with short life expectancies, who usually are not treated with standard chemotherapy.
\end{abstract}

Methods: The present analysis aims to describe clinicians' attitudes towards $\mathrm{ICl}$ s administration during late stages of life within a multicenter cohort of advanced cancer patients treated with single agent PD-1/PD-L1 checkpoint inhibitors in Italy.

Results: Overall, 1149 patients with advanced cancer who received single agent PD-1/PD-L1 checkpoint inhibitors were screened. The final study population consisted of 567 deceased patients. 166 patients (29.3\%) had received ICls within 30 days of death; among them there was a significantly higher proportion of patients with ECOG-PS $\geq 2$ (28.3\% vs $11.5 \%, p<0.0001)$ and with a higher burden of disease (69.3\% vs $59.4 \%, p=0.0266)$. In total, 35 patients (6.2\%) started ICls within 30 days of death; among them there was a higher proportion of patients with ECOG-PS $\geq 2(45.7 \%$ vs $14.5 \%, p<0.0001)$ and with a higher burden of disease ( $82.9 \%$ vs $60.9 \%, p=0.0266)$. Primary tumors were significantly different across subgroups $(p=0.0172)$, with a higher prevalence of NSCLC patients ( $80 \%$ vs $60.9 \%$ ) among those who started ICls within 30 days of death. Lastly, 123 patients (21.7\%) started ICls within 3 months of death. Similarly, within this subgroup there was a higher proportion of patients with ECOG-PS $\geq 2(29.3 \%$ vs $12.8 \%, \mathrm{p}<0.0001)$, with a higher burden of disease ( $74.0 \%$ vs $59.0 \%, p=0.0025)$ and with NSCLC (74.0\% vs 58.8\%, $p=0.0236)$.

\footnotetext{
*Correspondence: a.cortellini@imperial.ac.uk; alessiocortellini@gmail.com

${ }^{26}$ Department of Surgery and Cancer, Faculty of Medicine, Imperial

College London, Hammersmith Hospital, Du Cane Road, London W12

OHS, UK

Full list of author information is available at the end of the article
}

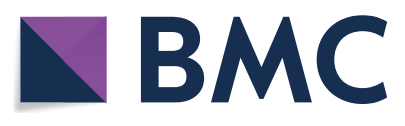

(c) The Author(s) 2021. This article is licensed under a Creative Commons Attribution 4.0 International License, which permits use, sharing, adaptation, distribution and reproduction in any medium or format, as long as you give appropriate credit to the original author(s) and the source, provide a link to the Creative Commons licence, and indicate if changes were made. The images or other third party material in this article are included in the article's Creative Commons licence, unless indicated otherwise in a credit line to the material. If material is not included in the article's Creative Commons licence and your intended use is not permitted by statutory regulation or exceeds the permitted use, you will need to obtain permission directly from the copyright holder. To view a copy of this licence, visit http://creativeco mmons.org/licenses/by/4.0/. The Creative Commons Public Domain Dedication waiver (http://creativecommons.org/publicdomain/ zero/1.0/) applies to the data made available in this article, unless otherwise stated in a credit line to the data. 
Conclusion: Our results confirmed a trend toward an increasing ICls prescription in frail patients, during the late stages of life. Caution should be exercised when evaluating an ICl treatment for patients with a poor PS and a high burden of disease.

Keywords: Immunotherapy, Immune checkpoint inhibitors, End-of-life, Palliative care, Appropriateness

\section{Introduction}

Several studies showed that palliative chemotherapy does not improve the quality of life $(\mathrm{QoL})$ of patients with end-stage cancer and has a detrimental effect in patients with good performance status due to toxicities [1-3]. After the advent of immune checkpoint inhibitors (ICIs), the treatment paradigm of several malignancies has radically changed, and although ICIs are associated with class-specific inflammatory side effects, namely immunerelated adverse events (irAEs), they are characterized by an overall favourable safety profile as compared to chemotherapy [4].

Clinician awareness of irAEs clinical presentation, diagnosis and management has increased over time. As consequence of this increasing confidence, attitudes towards ICIs prescription in frail patients, who are usually unfit for standard chemotherapy, might have increased too. This attitude has been described as "desperation oncology" [5], an unbalance between hope and reality that produces detrimental effects on the patient's QoL and might have a huge economic impact on healthcare systems $[6$, 7].

There is lacking literature exploring the use of ICIs during end-of-life stages, therefore, in the absence of high levels of evidence, some competitive factors could weigh on medical decisions, including reports of "miracles" found in all human-interest stories.

Against this background, we conducted this ad-hoc analysis within a large multicentre cohort of advanced cancer patients treated with single agent PD-1/PD-L1 checkpoint inhibitors in Italy.

\section{Materials and Methods Study design}

The aim of the present analysis was to describe clinicians' attitudes towards single agent PD-1/PD-L1 checkpoint inhibitors administration and prescription during late stages of life, among a multicenter cohort of advanced cancer patients treated in clinical practice in Italy [815] (Additional file 1, Table S1). This "ad-hoc" analysis has been performed on a cohort of patients already collected, after a follow-up update. Considering this, and the descriptive overarching aim, we did not perform a formal power calculation.
Following a request for a data update, 19 Institutions participated (Additional file 1: Table S1); consecutive patients with confirmed stage IV cancer who received immunotherapy from June 2014 to June 2020, as 1st or subsequent line were screened, data cut-off period was December 2020. Patients who died, with available information about the last administration of immunotherapy were included.

To provide a detailed picture of trends in ICIs administration during late stages of life we established the following clinical endpoints of interest:

- Having received ICIs within 30 days of death [16];

- Having started ICIs within 30 days of death [17];

- Having started ICIs within 3 months of death [18].

An explorative univariable analysis was also performed, in order to evaluate whether any baseline (at ICIs initiation) patient characteristics were associated with clinical endpoints of interests. The considered baseline features were: primary tumor types (NSCLC, melanoma, renal cell carcinoma and others), age $(<70$ $v s \geq 70$ years old $/<60 v s \geq 60$ years old), gender (male $v s$ female), Eastern Cooperative Oncology GroupPerformance Status (ECOG-PS) (0-1 vs $\geq 2)$, burden of disease (number of metastatic sites $\leq 2 v s>2$ ), and treatment line (first $v s$ second $v s$ further lines). Additionally, to depict the trends towards ICIs administration during late stages of life over time, we also reported the crude incidence of the three endpoints of interest across the years, clustered as follow: 20142015, 2016-2017, 2018-2020.

In order to provide further insights on clinicians' attitudes towards continuing ICIs until the late stages of life, the associations between administration of ICI within 30 days of death and best response to ICI/time to treatment failure (TTF) have been evaluated. Methods regarding response evaluation have been already reported [1-8]. Best response to ICIs was categorized as partial response (PR)/complete response (CR) vs stable disease (SD)/progressive disease (PD). Patients who did not undergo formal radiological assessment were excluded from this analysis. TTF was defined as the time from ICI initiation to treatment discontinuation for whatever cause and was categorized as $\geq 3$ months $v s<3$ months. Lastly, we also explored the achieved 
disease control rate (DCR, defined as the portion of patients experiencing $\mathrm{PR} / \mathrm{CR} / \mathrm{SD}$ ) among those patients who started ICI within 3 months of death who underwent a formal radiological assessment.

Baseline patient characteristics were reported with descriptive statistics. $\chi^{2}$ and Fisher's exact tests was used for all univariable analyses as appropriate. Median TTF was estimated evaluated using the Kaplan-Meier method. The alpha level for all analyses was set to $\mathrm{p}<0.05$. All statistical analyses were performed using MedCalc Statistical Software version 19.3.1 (MedCalc Software Ltd, Ostend, Belgium; https://www.medcalc.org; 2020).

\section{Results}

Overall, 1149 patients with advanced cancer who received single agent PD-1/PD-L1 checkpoint inhibitors were screened as part of the data update process. At data cut-off, 480 patients were alive while 102 patients had missing information about the last administration of immunotherapy. The final study population consisted of 567 deceased patients. Figure 1 reported the study flow diagram.

Table 1 summarizes baseline patient characteristics for the whole population and the subgroup analysis based on receipt of ICIs within 30 days of death. One hundred and sixty-six patients (29.3\%) received ICIs within 30 days of death. Among them there was a significantly higher proportion of patients with ECOG-PS $\geq 2(28.3 \%$ vs $11.5 \%$,

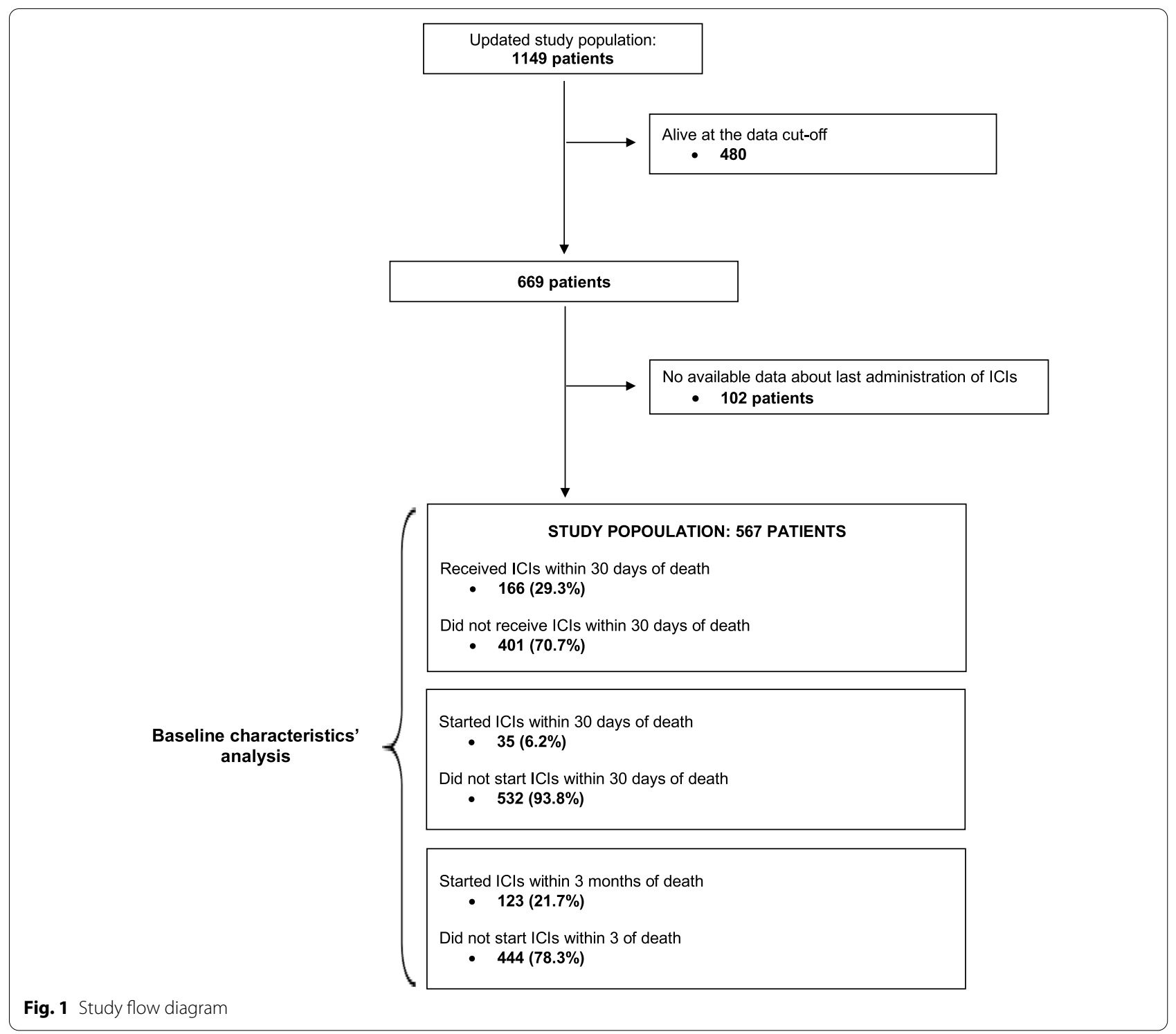


Table 1 Baseline characteristics of the overall study population and of patients grouped according to the receipt of ICls within 30 days of death

\begin{tabular}{|c|c|c|c|c|}
\hline & Overall & $\begin{array}{l}\text { No ICls administration within } \\
30 \text { days of death }\end{array}$ & $\begin{array}{l}\text { ICls administration within } \\
30 \text { days of death }\end{array}$ & \\
\hline & $\mathrm{N}^{\circ}(\%)$ & $\mathrm{N}^{\circ}(\%)$ & $\mathrm{N}^{\circ}(\%)$ & \\
\hline & 567 & 401 & 166 & \\
\hline \multicolumn{5}{|l|}{ Age } \\
\hline$<60$ years old & $148(26.1)$ & $111(27.7)$ & $37(22.3)$ & \multirow{4}{*}{$\begin{array}{l}P=0.1839 \\
P=0.9163\end{array}$} \\
\hline$\geq 60$ years old & $419(73.9)$ & $290(72.3)$ & $129(77.7)$ & \\
\hline$<70$ years old & $323(57.0)$ & $229(57.1)$ & $94(56.6)$ & \\
\hline$\geq 70$ years old & $244(43.0)$ & $172(42.9)$ & $72(43.4)$ & \\
\hline \multicolumn{4}{|l|}{ Gender } & \multirow[t]{3}{*}{$P=0.1600$} \\
\hline Female & $192(33.9)$ & $143(37.5)$ & $49(29.5)$ & \\
\hline Male & $375(66.1)$ & $258(64.3)$ & $117(70.5)$ & \\
\hline \multicolumn{4}{|l|}{ ECOG PS } & \multirow[t]{3}{*}{$P<0.0001$} \\
\hline $0-1$ & $474(83.6)$ & $355(88.5)$ & $119(71.7)$ & \\
\hline$\geq 2$ & $93(16.4)$ & $46(11.5)$ & $47(28.3)$ & \\
\hline \multicolumn{4}{|l|}{ Primary tumor } & \multirow[t]{5}{*}{$P=0.0707$} \\
\hline NSCLC & $352(62.1)$ & $239(59.6)$ & $113(68.2)$ & \\
\hline Melanoma & $111(19.6)$ & $89(22.2)$ & $22(13.3)$ & \\
\hline Renal cell carcinoma & $83(14.6)$ & $60(15.0)$ & $23(13.9)$ & \\
\hline Others & $21(3.7)$ & $13(3.2)$ & $8(4.8)$ & \\
\hline \multicolumn{4}{|l|}{ No. of metastatic sites } & \multirow[t]{3}{*}{$P=0.0266$} \\
\hline$\leq 2$ & $214(37.7)$ & $163(40.6)$ & $51(30.7)$ & \\
\hline$>2$ & $353(62.3)$ & $238(59.4)$ & $115(69.3)$ & \\
\hline \multicolumn{4}{|l|}{ Type of anti-PD-1/PD-L1 agent } & \multirow[t]{5}{*}{$P=0.5445$} \\
\hline Pembrolizumab & $168(29.6)$ & $123(30.7)$ & $45(27.1)$ & \\
\hline Nivolumab & $370(65.3)$ & $258(64.3)$ & $112(67.5)$ & \\
\hline Atezolizumab & $18(3.2)$ & $11(2.7)$ & $7(4.2)$ & \\
\hline Others & $11(1.9)$ & $9(2.2)$ & $2(1.2)$ & \\
\hline \multicolumn{4}{|l|}{ Treatment line } & \multirow[t]{4}{*}{$P=0.8895$} \\
\hline First & $173(30.5)$ & $123(30.7)$ & $50(28.9)$ & \\
\hline Second & $324(57.1)$ & $227(56.6)$ & $97(58.4)$ & \\
\hline Further lines & $70(12.3)$ & $51(12.7)$ & $19(11.4)$ & \\
\hline \multicolumn{4}{|l|}{ Best response ${ }^{a}$} & \multirow[t]{3}{*}{$P=0.4693$} \\
\hline $\mathrm{PR} / \mathrm{CR}$ & $403(79.5)$ & $300(78.7)$ & $103(81.7)$ & \\
\hline $\mathrm{PD} / \mathrm{SD}$ & $104(20.5)$ & $81(21.3)$ & $23(18.3)$ & \\
\hline \multicolumn{4}{|l|}{ Time to treatment failure } & \multirow[t]{3}{*}{$P=0.0028$} \\
\hline$\geq 3$ months & $308(54.3)$ & $234(58.4)$ & $74(44.6)$ & \\
\hline$<3$ months & $259(45.7)$ & $167(41.6)$ & $92(55.4)$ & \\
\hline
\end{tabular}

a 507 evaluable patients for best response. ICI: immune checkpoint inhibitor; ECOG-PS: eastern cooperative oncology group performance status; NSCLC: non-small cell lung cancer; PD-1/PD-L1: programmed death-1/programmed death-ligand 1; PR: partial response; CR: complete response; PD: progressive disease; SD: stable disease

$\mathrm{p}<0.0001)$ and with a higher burden of disease $(69.3 \%$ vs $59.4 \%, \mathrm{p}=0.0266)$. No significant association was found with respect to age $(\mathrm{p}=0.9163)$, gender $(\mathrm{p}=0.1600)$, primary tumor $(\mathrm{p}=0.0707)$ or treatment line $(\mathrm{p}=0.8895)$. Administration of ICIs within 30 days of death was associated with a shorter TTF (55.4\% vs $41.6 \%, \mathrm{p}=0.0028)$, while no association with the achieved best response was reported.
Overall, 35 patients $(6.2 \%)$ started ICIs within 30 days of death (Table 2); among them there was a higher proportion of patients with ECOG-PS $\geq 2$ (45.7\% vs $14.5 \%$, $\mathrm{p}<0.0001)$ and with a higher burden of disease $(82.9 \%$ vs $60.9 \%, p=0.0266)$. No significant association was found with respect to age $(p=0.2810)$, gender $(p=0.7536)$, or treatment line $(\mathrm{p}=0.1822)$, while primary tumors were significantly different across the subgroup $(\mathrm{p}=0.0172)$, 
with a high prevalence of NSCLC patients (80\% vs 60.9\%) among those who started ICIs within 30 days of death.

In total, 123 patients $(21.7 \%)$ started ICIs within 3 months of death (Table 3). Similarly, within this subgroup there was a higher proportion of patients with ECOG-PS $\geq 2(29.3 \%$ vs $12.8 \%, p<0.0001)$, with a higher burden of disease $(74.0 \%$ vs $59.0 \%, \mathrm{p}=0.0025)$ and with NSCLC (74.0\% vs $58.8 \%, \mathrm{p}=0.0236)$. Treatment line distribution was also significantly different between patients who and who did not started ICIs within 3 months of death $(p=0.0189)$, while no association was reported regarding gender $(\mathrm{p}=0.3171)$ and age $(\mathrm{p}=0.8261)$. Among the 80 evaluable patients who started ICIs within 3 months of death, the DCR was 3.7\% (95\%CI: $0.77-$ 10.9), while among the 427 who did not start ICIs within 3 months of death DCR was 54.1\% (95\%CI: 47.3-61.5) $(\mathrm{p}<0.0001)$.

Figure 2 reports the analysis of the three endpoints of interest over time, clearly revealing an increasing trend of ICIs administration within 30 days and ICIs initiation within 30 days/ 3 months of death, over the years.

\section{Discussion}

An increasing tendency towards ICIs prescription and administration during end-of-life stages has been already reported. A multicenter analysis of advanced urothelial carcinoma patients reported an increase of ICIs administration within 60 days of death, from 1 to $23 \%$ between the final quarter of 2015 and 2017, respectively [19]. Similarly, Glisch and colleagues reported that patients receiving ICIs within 30 days of death have a poorer PS, do not
Table 2 Patients' characteristics according to $\mathrm{ICls}$ initiation within 30 days of death

\begin{tabular}{|c|c|c|c|}
\hline & Control & $\begin{array}{l}\text { ICls started within } \\
30 \text { days of death }\end{array}$ & \\
\hline & $\mathrm{N}^{\circ}(\%)$ & $\mathrm{N}^{\circ}(\%)$ & \\
\hline & $532(93.8)$ & $35(6.2)$ & \\
\hline Age & & & \\
\hline$<60$ years old & $142(26.7)$ & $6(17.1)$ & $P=0.2132$ \\
\hline$\geq 60$ years old & $390(73.3)$ & $29(82.9)$ & $P=0.2810$ \\
\hline$<70$ years old & $300(56.4)$ & $23(65.7)$ & \\
\hline$\geq 70$ years old & $232(43.6)$ & $12(34.3)$ & \\
\hline Gender & & & $P=0.7536$ \\
\hline Female & $181(34.0)$ & $11(31.4)$ & \\
\hline Male & $351(66.0)$ & $24(68.6)$ & \\
\hline ECOG PS & & & $P<0.0001$ \\
\hline $0-1$ & $455(85.5)$ & $19(54.3)$ & \\
\hline$\geq 2$ & $77(14.5)$ & $16(45.7)$ & \\
\hline Primary tumor & & & $P=0.0172$ \\
\hline NSCLC & $324(60.9)$ & $28(80)$ & \\
\hline Melanoma & $108(20.3)$ & $3(8.6)$ & \\
\hline Renal cell carcinoma & $82(15.4)$ & $1(2.9)$ & \\
\hline Others & $18(3.4)$ & $3(8.6)$ & \\
\hline No. of metastatic sites & & & $P=0.0095$ \\
\hline$\leq 2$ & $208(39.1)$ & $6(17.1)$ & \\
\hline$>2$ & $324(60.9)$ & $29(82.9)$ & \\
\hline Treatment line & & & $P=0.1822$ \\
\hline First & $158(29.7)$ & $15(42.9)$ & \\
\hline Second & $306(57.5)$ & $18(51.4)$ & \\
\hline Further lines & 68 (12.8) & $2(5.7)$ & \\
\hline
\end{tabular}

ICl: immune checkpoint inhibitor; ECOG-PS: eastern cooperative oncology group-performance status; NSCLC: non-small cell lung cancer

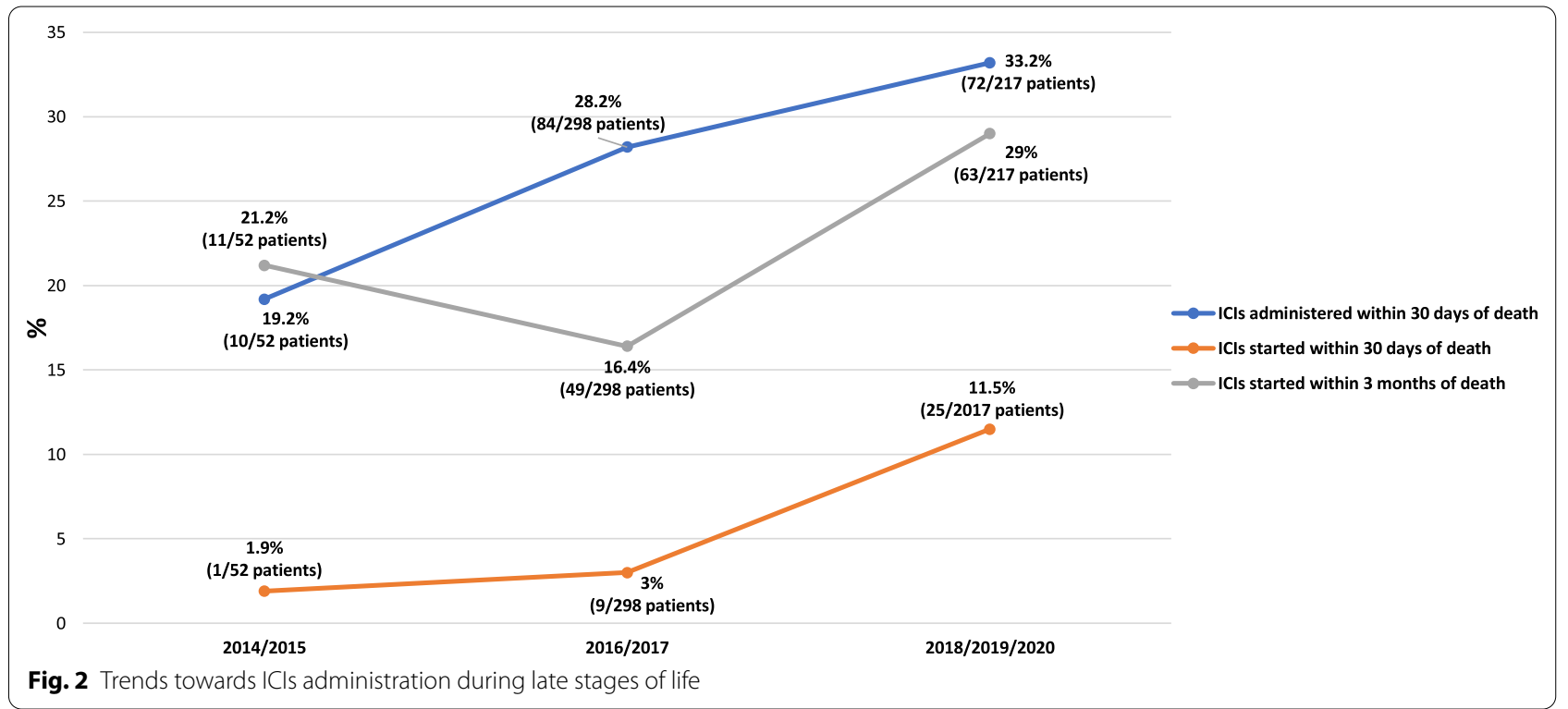


receive subsequent anticancer treatments and are more likely to die in hospital rather than in hospice [20]. Analogous results have also been demonstrated among NSCLC patients [21], while Durbin et al. specifically described a cohort of patients initiating ICIs in the inpatient setting, confirming their poor overall outcome [22].

Our study confirmed that in clinical practice, a not negligible portion of patients received immunotherapy with single agent PD-1/PD-L1 inhibitors within 30 days of death, as well as started ICIs within 3 months/30 days of death. Overall, these patients had a high burden of disease, presented features of frailty such as poorer PS, and in the subgroup of patients initiating ICI within 3 months of death were often being treated with an advanced line of therapy. We also found that those who started ICIs within 3 months and 30 days of death were more likely to be NSCLC patients, mirroring what have been already reported by Durbin et al. [22]. Even this finding reflects a feature of frailty, as NSCLC is known to be a more aggressive disease as compared to melanoma and renal cell carcinoma. Unsurprisingly, the achieved clinical outcomes for patients who initiated ICIs within 3 months of death were disappointing with a DCR of $3.7 \%$.

Interestingly, the attitude of administering ICIs during the late stages of life was not associated with patient age in our cohort, supporting that age does not impair ICI efficacy [23, 24], while decision to continue ICIs until the late stages of life did not depend on previous clinical benefit, confirming that the choice to extend ICIs therapy beyond a clinically useful time window is (often) founded by a "desperation" approach, rather than guided by evidence of previous clinical benefit.

Our exploratory analysis of ICI prescribing trends over time, clearly confirmed that there is a recent increasing tendency for clinicians to trial ICI therapy in very advanced cancer patients, likely depicting increasing confidence in prescribing ICIs for frail patients, during the late stages of life, relative to that reported with standard chemotherapy $[16,17]$. These findings, if on one hand reflect the better safety profile of ICIs, which allows their administration in patients unfit for chemotherapy, on the other hand must make us pause for thought. Though a proper life expectancy estimation might be challenging and inaccurate, we clearly revealed that caution should be exercised when considering ICI treatment for patients (especially NSCLC) with a poor PS, a high burden of disease, and in an advance line of treatment. These hallmarks of frailty might represent a wake-up call for clinicians, to take into consideration to ensure appropriateness of ICI prescription.

However, our study reports a snapshot of the Italian clinical practice, which has its own peculiarities. The National Health System in Italy is "universalistic",
Table 3 Patients' characteristics according to ICls initiation within 3 months of death

\begin{tabular}{|c|c|c|c|}
\hline & Control & $\begin{array}{l}\text { ICls started within } \\
3 \text { months of death }\end{array}$ & \\
\hline & $\mathrm{N}^{\circ}(\%)$ & $\mathrm{N}^{\circ}(\%)$ & \\
\hline & $444(78.3)$ & $123(21.7)$ & \\
\hline \multicolumn{4}{|l|}{ Age } \\
\hline$<60$ years old & $124(27.9)$ & $24(19.5)$ & \multirow{4}{*}{$\begin{array}{l}P=0.0603 \\
P=0.8261\end{array}$} \\
\hline$\geq 60$ years old & $320(72.1)$ & 99 (80.5) & \\
\hline$<70$ years old & $254(57.2)$ & $69(56.1)$ & \\
\hline$\geq 70$ years old & $190(42.8)$ & $54(43.9)$ & \\
\hline \multicolumn{3}{|l|}{ Gender } & \multirow[t]{3}{*}{$P=0.3171$} \\
\hline Female & $155(34.9)$ & $37(30.1)$ & \\
\hline Male & $289(65.1)$ & $86(69.9)$ & \\
\hline \multicolumn{3}{|l|}{ ECOG PS } & \multirow[t]{3}{*}{$P<0.0001$} \\
\hline $0-1$ & $387(87.2)$ & $87(70.7)$ & \\
\hline$\geq 2$ & $57(12.8)$ & $36(29.3)$ & \\
\hline \multicolumn{3}{|l|}{ Primary tumor } & \multirow[t]{5}{*}{$P=0.0236$} \\
\hline NSCLC & $261(58.8)$ & $91(74.0)$ & \\
\hline Melanoma & $94(21.2)$ & $17(13.8)$ & \\
\hline Renal cell carcinoma & $71(16.0)$ & $12(9.8)$ & \\
\hline Others & $18(4.1)$ & $3(2.4)$ & \\
\hline \multicolumn{3}{|l|}{ No. of metastatic sites } & \multirow[t]{3}{*}{$P=0.0025$} \\
\hline$\leq 2$ & $182(41.0)$ & $32(26.0)$ & \\
\hline$>2$ & $262(59.0)$ & $91(74.0)$ & \\
\hline \multicolumn{3}{|l|}{ Treatment line } & \multirow[t]{4}{*}{$P=0.0189$} \\
\hline First & $138(31.1)$ & $35(28.5)$ & \\
\hline Second & $243(54.7)$ & $81(65.9)$ & \\
\hline Further lines & $63(14.2)$ & $7(5.7)$ & \\
\hline
\end{tabular}

$\mathrm{ICl}$ : immune checkpoint inhibitor; ECOG-PS: eastern cooperative oncology group-performance status; NSCLC: non-small cell lung cancer

meaning that it is entirely government-funded and guarantees costly therapies and procedures to all oncological patients, regardless of their income or insurance status. Although this approach protects the welfare of all citizens, ensuring free access to care and services equitably, other healthcare systems with mixed coverage schemes (e.g. with private health insurances), might be more efficient in monitoring and analyzing the cost/benefit ratio of anticancer treatments, as clearly reported by Glisch $\mathrm{C}$ et al. and Durbin SM et al. [2022]. Nonetheless, the Italian drug regulatory agency, namely AIFA (Agenzia Italiana del Farmaco), has an on-line monitoring dashboard for high-cost drugs, including ICIs, to ensure prescription appropriateness.

This study acknowledged several limitations beyond the retrospective design and the risk of selection bias. The dataset had not been designed for this analysis 
therefore we did not have information about possible treatment lines following ICIs, further hospice referrals or alternative treatment choices at ICIs initiation including clinical trials, nor about formal assessment of life expectancy at ICIs initiation. Additionally, we were unable to perform a detailed cost/benefit analysis and we did not report the irAEs incidence among the study population.

\section{Conclusion}

Our results confirmed a trend toward increasing ICIs prescription in frail patients during the late stages of life, particularly as compared to that reported for standard chemotherapy, with questionable efficacy. Patients who received ICIs within 30 days of death and patients who started them within 3 months/30 days of death had most of the hallmarks of frailty, including a poor PS and a high burden of disease. Caution should be exercised when evaluating an considering ICIs treatment for these patients, in order to ensure an appropriate ICIs administration.

\section{Supplementary Information}

The online version contains supplementary material available at https://doi. org/10.1186/s12967-021-02937-9.

Additional file 1: Table S1

\section{Acknowledgements}

None.

\section{Novelty and impact statements}

Immune checkpoint inhibitors (ICls) have revolutionized the treatment algorithms of several malignancies. ICls are characterized by a favorable safety profile as compared with standard chemotherapy and the increasing confidence with ICls might have led to an increasing prescription even in frail patients, unfit for standard chemotherapy and with short life expectancies. We confirmed the increasing trend towards $\mathrm{ICl}$ s prescription and administration in late stages of life. Performance status and burden of disease still remain the major clinical determinants.

\section{Authors' contributions}

All authors contributed to the publication according to the ICMJE guidelines for the authorship. All authors agreed to be accountable for all aspects of the research in ensuring that the accuracy or integrity of any part of the work are appropriately investigated and resolved. All authors read and approved the final manuscript.

\section{Funding}

No funding was received.

\section{Availability of data and materials}

The datasets used during the present study are available from the corresponding author upon reasonable request.

\section{Declarations}

Ethics approval and consent to participate

The procedures followed were in accordance with the precepts of Good Clinical Practice and the declaration of Helsinki. The study was approved by the respective local ethical committees on human experimentation of each institution, after previous approval by the coordinating center (University of L'Aquila, Internal Review Board protocol number 32865, approved on July 24th, 2018).

\section{Consent for publication}

Not applicable.

\section{Competing interests}

Dr Sebastiano Buti received honoraria as speaker at scientific events and advisory role by Bristol-Myers Squibb (BMS), Pfizer; MSD, Ipsen, Roche, Eli-Lilly, AstraZeneca and Novartis. Dr. Melissa Bersanelli received research funding by Roche, Seqirus, Pfizer and Novartis, personal fees as speaker/consultant by AstraZeneca, Novartis, Pfizer, BMS. Dr Raffaele Giusti received speaker fees and grant consultancies from AstraZeneca and Roche. Dr Maria G Vitale received speaker fees, grant consultancies and travel support from BMS, Ipsen, Novartis, Pfizer, Astellas, Jansen and Pierre-Fabre. Dr Alessandro Russo received grant consultancies from AstraZeneca and MSD. Dr Francesco Spagnolo received speaker fees and grant consultancies from Roche, Novartis, BMS, MSD, PierreFabre, Sanofi, Merck and Sunpharma. Paolo A. Ascierto has/had a consultant/ advisory role for Bristol Myers Squibb, Roche-Genentech, Merck Sharp \& Dohme, Novartis, Array, Merck Serono, Pierre-Fabre, Incyte, Medimmune, AstraZeneca, Syndax, Sun Pharma, Sanofi, Idera, Ultimovacs, Sandoz, Immunocore, 4SC, Alkermes, Italfarmaco, Nektar, Boehringer-Ingelheim, Eisai, Regeneron, Daiichi Sankyo, Pfizer, Oncosec, Nouscom, Takis, Lunaphore, Seagen. He also received research funding from Bristol Myers Squibb, Roche-Genentech, Array, Sanofi and travel support from MSD. Dr David J. Pinato received lecture fees from ViiV Healthcare, Bayer Healthcare and travel expenses from BMS and Bayer Healthcare; consulting fees for Mina Therapeutics, EISAI, Roche, Astra Zeneca; received research funding (to institution) from MSD, BMS. Dr Alessio Cortellini received speaker fees and grant consultancies from Roche, MSD, BMS, AstraZeneca, Novartis, Astellas. All other authors declared no competing interests.

\section{Author details}

${ }^{1}$ Medical Oncology, Campus Bio-Medico University, Rome, Italy. ${ }^{2}$ Medical Oncology Unit, University Hospital of Parma, Parma, Italy. ${ }^{3}$ Medical Oncology Unit, Department of Biomedical Sciences and Human Oncology, University of Bari, Bari, Italy. ${ }^{4}$ National Cancer Research Center, Tumori Institute IRCCS Giovanni Paololl, Bari, Italy. ${ }^{5}$ Medical Oncology, A.O. Papardo \& Department of Human Pathology, University of Messina, Messina, Italy. ${ }^{6}$ Department of Medicine and Surgery, University of Parma, Parma, Italy. ${ }^{7}$ IRCCS Ospedale Policlinico San Martino, Genova, Italy. ${ }^{8}$ UOC Oncologia Ascoli Piceno - San Benedetto del Tronto, Area Vasta 5, ASUR Marche, Ancona, Italy. ${ }^{9}$ Medical Oncology Unit, Sant'Andrea Hospital of Rome, Rome, Italy. ${ }^{10}$ Department of Clinical and Molecular Medicine, Sapienza University of Rome, Rome, Italy. ${ }^{11}$ Medical Oncology (B), Policlinico Umberto I,"Sapienza" University of Rome, Rome, Italy. ${ }^{12}$ Medical Oncology, Azienda Ospedaliero-Universitaria Pisana, Pisa, Italy. ${ }^{13}$ Medical Oncology, University Hospital of Modena, Modena, Italy. ${ }^{14}$ UOC Oncologia Padova Sud - AULSS6 Euganea, Padova, Italy. ${ }^{15}$ Medical Oncology Unit, Fondazione IRCCS Ca Granda Ospedale Maggiore Policlinico, Milan, Italy. ${ }^{16}$ Medical Oncology, ASST Sette Laghi, Ospedale di Circolo e Fondazione Macchi, Varese, Italy. ${ }^{17}$ Division of Medical Oncology, University of Insubria, Varese, Italy. ${ }^{18}$ Department of Medical, Oral \& Biotechnological Sciences, University G. D'Annunzio, Chieti-Pescara, Italy. ${ }^{19} \mathrm{Clinical}$ Oncology Unit, S.S. Annunziata Hospital, Chieti, Italy. ${ }^{20}$ Division of Medical Oncology for Melanoma, Sarcoma, and Rare Tumors, IEO, European Institute of Oncology IRCCS, Milan, Italy. ${ }^{21}$ S.C. Medical Oncology, Azienda Ospedaliera S. Maria, Terni, Italy. ${ }^{22}$ Oncology Unit, IRCCS Ospedale Sacro Cuore Don Calabria, Negrar, VR, Italy. ${ }^{23}$ Medical Oncology, Santa Maria Goretti Hospital, Latina, Italy. ${ }^{24}$ Genetics of Rare Cancers, Department of Internal Medicine and Medical Specialties, University of Genoa, Genoa, Italy. ${ }^{25}$ Melanoma, Cancer Immunotherapy and Development Therapeutics Unit, Istituto Nazionale Tumori-IRCCS Fondazione "G. Pascale", Naples, Italy. ${ }^{26}$ Department of Surgery and Cancer, Faculty of Medicine, Imperial College London, Hammersmith Hospital, Du Cane Road, London W12 OHS, UK. ${ }^{27}$ Division of Oncology, Department of Translational Medicine, University of Piemonte Orientale, Novara, Italy. ${ }^{28}$ Medical Oncology Unit, St. Salvatore Hospital, L'Aquila, Italy. ${ }^{29}$ Department of Biotechnological and Applied Clinical Sciences, University of L'Aquila, L'Aquila, Italy. 
Received: 1 May 2021 Accepted: 11 June 2021

Published online: 24 June 2021

\section{References}

1. Ersek M, Miller SC, Wagner TH, Thorpe JM, Smith D, Levy CR, et al. Association between aggressive care and bereaved families' evaluation of end-of-life care for veterans with non-small cell lung cancer who died in Veterans Affairs facilities. Cancer. 2017;123(16):3186-94.

2. Batra A, McKinnon G, Billawala A, Sheka D, Kong S, Cheung WY. Factors associated with the initiation of chemotherapy within 90 days of death in metastatic colorectal cancer patients: a population-based study. Support Care Cancer. 2021;29(3):1535-42.

3. Hashimoto K, Yonemori K, Katsumata N, Hotchi M, Kouno T, Shimizu C, et al. Factors that affect the duration of the interval between the completion of palliative chemotherapy and death. Oncologist. 2009;14(7):752-9.

4. Kennedy LB, Salama AKS. A review of cancer immunotherapy toxicity. CA Cancer J Clin. 2020;70(2):86-104.

5. Fojo T. Desperation oncology. Semin Oncol. 2018:45(3):105-6.

6. Garrido MM, Prigerson HG, Bao Y, Maciejewski PK. chemotherapy use in the months before death and estimated costs of care in the last week of life. J Pain Symptom Manage. 2016;51(5):875-81.e2.

7. Schnipper LE, Smith TJ, Raghavan D, Blayney DW, Ganz PA, Mulvey TM, et al. American Society of Clinical Oncology identifies five key opportunities to improve care and reduce costs: the top five list for oncology. J Clin Oncol. 2012;30(14):1715-24.

8. Cortellini A, Bersanelli M, Buti S, et al. A multicenter study of body mass index in cancer patients treated with anti-PD-1/PD-L1 immune checkpoint inhibitors: when overweight becomes favorable. J Immunother Cancer. 2019:7(1):57. https://doi.org/10.1186/s40425-019-0527-y.

9. Cortellini A, Bersanelli M, Santini D, et al. Another side of the association between body mass index (BMI) and clinical outcomes of cancer patients receiving programmed cell death protein-1 (PD-1)/ Programmed cell death-ligand 1 (PD-L1) checkpoint inhibitors: A multicentre analysis of immune-related adverse events. Eur J Cancer. 2020;128:17-26. https:// doi.org/10.1016/j.ejca.2019.12.031.

10. Cortellini A, Buti S, Bersanelli M, et al. Evaluating the role of FAMlly history of cancer and diagnosis of multiple neoplasms in cancer patients receiving PD-1/PD-L1 checkpoint ihibitors: the multicenter FAMI-L1 study. Oncoimmunology. 2020;9(1):1710389. https://doi.org/10.1080/2162402X. 2019.1710389

11. Cortellini A, Vitale MG, de Galitiis F, et al. Early fatigue in cancer patients receiving PD-1/PD-L1 checkpoint inhibitors: an insight from clinical practice. J Transl Med. 2019;17(1):376. https://doi.org/10.1186/ s12967-019-02132-x.

12. Cortellini A, Buti S, Santini D, et al. Clinical outcomes of patients with advanced cancer ad pre-existing autoimmune diseases treated with anti-programmed death-1 immunotherapy: a real-world transverse study. Oncologist. 2019;24(6):e327-37. https://doi.org/10.1634/theoncologist. 2018-0618.

13. Cortellini A, Chiari R, Ricciuti B, et al. Correlations between the immunerelated adverse events spectrum and efficacy of anti-PD1 Immunotherapy in NSCLC Patients. Clin Lung Cancer. 2019;20(4):237-247.e1. https:// doi.org/10.1016/j.cllc.2019.02.006.
14. Cortellini A, Tucci M, Adamo V, et al. Integrated analysis of concomitant medications and oncological outcomes from PD-1/PD-L1 checkpoint inhibitors in clinical practice. J Immunother Cancer. 2020;8(2): e001361. https://doi.org/10.1136/jitc-2020-001361.

15. Buti S, Bersanelli M, Perrone F, et al. Effect of concomitant medications with immune-modulatory properties on the outcomes of patients with advanced cancer treated with immune checkpoint inhibitors: development and validation of a novel prognostic index. Eur J Cancer. 2021;142:18-28. https://doi.org/10.1016/j.ejca.2020.09.033 (Epub 2020 Nov 16).

16. Zhang Z, Chen ML, Gu XL, Liu MH, Zhao WW, Cheng WW. Palliative chemotherapy near the end of life in oncology patients. Am J Hosp Palliat Care. 2018;35(9):1215-20. https://doi.org/10.1177/1049909118763338 (Epub 2018 Mar 12).

17. Earle CC, Landrum MB, Souza JM, et al. Aggressiveness of cancer care near the end of life: is it a quality-of-care issue? [published correction appears in J Clin Oncol. 2010;28(19):3205] [published correction appears in J Clin Oncol. 2011;29(33):4472]. J Clin Oncol. 2008;26(23):3860-3866. doi:https://doi.org/10.1200/JCO.2007.15.8253

18. Jin S, Pazdur R, Sridhara R. Re-evaluating eligibility criteria for oncology clinical trials: analysis of investigational new drug applications in 2015. J Clin Oncol. 2017;35(33):3745-52. https://doi.org/10.1200/JCO.2017.73. 4186.

19. Parikh RB, Galsky MD, Gyawali B, Riaz F, Kaufmann TL, Cohen AB, et al. Trends in checkpoint inhibitor therapy for advanced urothelial cell carcinoma at the end of life: insights from real-world practice. Oncologist. 2019;24(6):e397-9.

20. Glisch C, Hagiwara Y, Gilbertson-White S, Gao Y, Lyckholm L. Immune checkpoint inhibitor use near the end of life is associated with poor performance status, lower hospice enrollment, and dying in the hospital. Am J Hosp Palliat Care. 2020;37(3):179-84.

21. Petrillo LA, El-Jawahri A, Nipp RD, Lichtenstein MRL, Durbin SM, Reynolds $\mathrm{KL}$, et al. Performance status and end-of-life care among adults with nonsmall cell lung cancer receiving immune checkpoint inhibitors. Cancer. 2020;126(10):2288-95.

22. Durbin SM, Zubiri L, Niemierko A, Bardia A, Sullivan RJ, McEwen C, et al. Clinical outcomes of patients with metastatic cancer receiving immune checkpoint inhibitors in the inpatient setting. Oncologist. 2021;26(1):49-55

23. Ninomiya K, Oze I, Kato Y, Kubo T, Ichihara E, Rai K, Ohashi K, Kozuki T, Tabata M, Maeda Y, Kiura K, Hotta K. Influence of age on the efficacy of immune checkpoint inhibitors in advanced cancers: a systematic review and meta-analysis. Acta Oncol. 2020;59(3):249-56. https://doi.org/10. 1080/0284186X.2019.1695062 (Epub 2019 Nov 29).

24. Landre T, Des Guetz G, Chouahnia K, Fossey-Diaz V, Culine S. Immune checkpoint inhibitors for patients aged $\geq 75$ years with advanced cancer in first- and second-line settings: a meta-analysis. Drugs Aging. 2020;37(10):747-54. https://doi.org/10.1007/s40266-020-00788-5.

\section{Publisher's Note}

Springer Nature remains neutral with regard to jurisdictional claims in published maps and institutional affiliations.

Ready to submit your research? Choose BMC and benefit from:

- fast, convenient online submission

- thorough peer review by experienced researchers in your field

- rapid publication on acceptance

- support for research data, including large and complex data types

- gold Open Access which fosters wider collaboration and increased citations

- maximum visibility for your research: over 100M website views per year

At $\mathrm{BMC}$, research is always in progress.

Learn more biomedcentral.com/submissions 